\title{
Impact of Newly Diagnosed Abnormal Glucose Tolerance on Long-Term Prognosis in Patients With Acute Myocardial Infarction
}

\author{
Koichi Tamita, MD; Minako Katayama, MD; Tsutomu Takagi, MD; \\ Takashi Akasaka, MD*; Atsushi Yamamuro, MD; Shuichiro Kaji, MD; \\ Shigefumi Morioka, MD; Yasuki Kihara, MD
}

\begin{abstract}
Background Newly-diagnosed diabetes mellitus (DM) and impaired glucose tolerance are common among patients with acute myocardial infarction (AMI). However, its significance on long-term clinical outcomes in those patients remains unclear. The present study was designed to determine whether such abnormalities after AMI affect long-term clinical outcomes.

Methods and Results Two-hundred and seventy-five AMI patients were prospectively enrolled. Eighty-five had diagnosed DM, while the other 190 did not. According to oral glucose tolerance tests at discharge, non-DM patients were divided into 2 groups: 78 patients with normal glucose tolerance and 112 patients with abnormal glucose tolerance. Patients were followed until they reached the primary endpoint: cardiovascular death or unplanned hospitalization due to major adverse cardiovascular events. The median follow-up period was 5.3 years. Kaplan-Meier survival curves for the abnormal glucose tolerance group were poorer than for normal glucose tolerance, and were equivalent to the pre-diagnosed DM group in prognosis $(\mathrm{p}<0.0005)$. Glucometabolic status was the strongest predictor for future cardiovascular events (hazard ratio to normal glucose tolerance; 2.65 ; confidence interval: $1.37-5.15 ; \mathrm{p}=0.004$ in abnormal glucose tolerance and 3.27:1.68-6.38; $\mathrm{p}=0.0005$ in $\mathrm{DM}$ ).

Conclusions Abnormal glucose tolerance in patients with AMI is a major risk factor for future cardiovascular events and may critically distinguish high-risk individuals. (Circ J 2007; 71: 834-841)
\end{abstract}

Key Words: Abnormal glucose tolerance; Diabetes mellitus; Myocardial infarction; Prognosis

C ompared to individuals without diabetes mellitus (DM), DM patients have approximately a 2-fold higher risk of short-term mortality after acute myocardial infarction (AMI)!,2 In the current reperfusion era, over $90 \%$ of DM patients survive the early 30 -day period; however, these patients are prone to markedly-increased mortality after $6^{\text {th }}$ months, 3,4 The results of several clinical studies indicate that even people with pre-diabetic conditions, such as impaired glucose tolerance (IGT), have increased risks for cardiovascular disease ${ }^{5-8} \mathrm{~A}$ recent metaregression analysis reported a continuous relationship between 2h-postchallenge glucose levels and cardiovascular risk below the diabetic threshold, and there is growing epidemiological evidence for the association of postchallenge hyperglycemia and macrovascular complications. ${ }^{9-13}$

Recently, the Glucose Tolerance in Patients with Acute Myocardial Infarction (GAMI) study revealed that abnormal glucose tolerance, determined by the presence of postchallenge hyperglycemia, was common among patients with AMI and is a risk factor for future cardiovascular events 14,15 However, the impact of newly-diagnosed abnor-

(Received October 13, 2006; revised manuscript received February 22, 2007; accepted March 15, 2007)

Department of Cardiovascular Medicine, Kobe General Hospital, Kobe, Japan

* Present address: Division of Cardiology, Wakayama Medical University, Wakayama, Japan.

Mailing address: Koichi Tamita, MD, Department of Cardiovascular Medicine, Kobe General Hospital, 4-6 Minatojima-nakamachi, Chuoku, Kobe 650-0046, Japan. E-mail: k-tamita@kcgh.gr.jp mal glucose tolerance on the long-term prognosis after AMI has not been fully demonstrated. The aim of the present study, therefore, was to determine whether newlydiagnosed abnormal glucose tolerance affects long-term clinical outcomes after AMI relative to AMI patients with normal glucose tolerance or with previously diagnosed DM in the current clinical settings.

\section{Methods}

Study Patients

We enrolled 384 consecutive patients with AMI admitted to the coronary care unit of Kobe General Hospital, Japan, from August 1997 to December 2000. We excluded all individuals who were older than 80 years old, or who had serum creatinine concentrations higher than $2.0 \mathrm{mg} / \mathrm{dl}$ or other inhospital major adverse clinical events, including cardiogenic shock and emergency coronary artery bypass grafting. Of the 384 consecutive patients screened, 109 patients were excluded due to in-hospital death $(n=34)$, stroke $(n=2)$, emergency coronary artery bypass surgery $(n=22)$, left ventricular $(\mathrm{LV})$ reconstruction surgery $(\mathrm{n}=2)$, non-fatal LV rupture $(n=5)$, recurrent percutaneous coronary intervention (PCI; $n=3$ ), concomitant disease ( $n=6$, idiopathic dilated cardiomyopathy, neoplasm, schizophrenia, hypoxic brain damage), chronic renal failure $(n=7)$, age over 80 years old $(n=8)$ and unwillingness to enter the study $(\mathrm{n}=20)$. The study protocol was approved by the Committee for the Protection of Human Subjects in Research at Kobe General Hospital. Written informed consent was obtained from all individuals. 


\section{Protocols}

The diagnosis of AMI was based on typical chest pain lasting more than $30 \mathrm{~min}$, new Q-waves in at least 2 continuous leads of the standard 12-lead ECG, changes in the electrocardiogram indicating acute ischemia or an increase in creatine kinase $(\mathrm{CK})$ concentration to twice the upper limit of normal range. Serum CK was measured serially every $3 \mathrm{~h}$ after admission until a peak value was obtained. The cardiac rehabilitation program for each patient was provided on the $2^{\text {nd }}$ week after admission.

We analyzed blood glucose concentrations in capillary whole blood immediately after admission. Glycosylated hemoglobin $\mathrm{A}_{1 \mathrm{c}}\left(\mathrm{HbA}_{1 \mathrm{c}}\right)$ was measured with a Hi-Auto A1c HA-8121 (Kyoto Kagaku, Kyoto, Japan) on the first morning after admission. In patients without previously diagnosed DM, a standard $75 \mathrm{~g}$ oral glucose tolerance test (OGTT) was undertaken at the time of discharge (around the $14^{\text {th }}$ hospital day). The plasma glucose level was measured using an enzymatic method with a Glucose Analyzer 1140 (Kyoto Daiichi Kagaku, Kyoto, Japan).

The glucometabolic status of each patient before hospitalization was evaluated by reviewing the outpatient records of our own or referring hospitals. Patients were classified as having previously diagnosed DM if they had a history of $\mathrm{DM}$ or if they were on a diet or medical treatments for DM. Patients with elevated fasting glucose levels $(\geq 126 \mathrm{mg} / \mathrm{dl})$ at the time of discharge were also categorized as having previously diagnosed DM.

The remaining patients were divided into 2 groups according to their 2-h plasma glucose levels, adopted by the WHO definition from 1998 and the fasting blood glucose criteria adopted by the American Diabetes Association recommendation from 1997!6,17 Namely, we classified patients as having newly diagnosed DM if their 2-h post-load plasma glucose concentrations $\geq 200 \mathrm{mg} / \mathrm{dl}$. IGT was defined as a fasting plasma glucose $<126 \mathrm{mg} / \mathrm{dl}$ and a 2 -h plasma glucose of $140-199 \mathrm{mg} / \mathrm{dl}$. The term newly-diagnosed abnormal glucose tolerance was used to describe the presence of newly-diagnosed DM or IGT. Normal glucose tolerance was defined as a fasting plasma glucose $<126 \mathrm{mg} / \mathrm{dl}$ and a 2 -h blood glucose $<140 \mathrm{mg} / \mathrm{dl}$. Impaired fasting glucose (IFG) was defined as a fasting plasma glucose of 110$125 \mathrm{mg} / \mathrm{dl}$.

Total cholesterol, high-density lipoprotein-cholesterol and triglyceride levels were measured using standard methods at the time of discharge. The concentration of lowdensity lipoprotein-cholesterol was estimated using the Friedewald equation for subjects who had fasting triglyceride levels $<400 \mathrm{mg} / \mathrm{dl}$ ! $^{18}$

Patients who received PCI with stent implantation were started on ticlopidine (100 mg twice a day) and aspirin ( $81 \mathrm{mg}$ twice a day) for 2 months. All patients were treated according to clinical presentation by their attending physicians without any attention to the results of OGTT during the follow-up period. The patients visited the outpatient clinic monthly for the first 6 months, then every 2 or 3 months until the final visit.

\section{Study Endpoints and Definitions}

Cardiovascular death was defined as death from myocardial infarction, stroke or sudden death without any obvious reasons. Acute coronary syndrome (ACS) was defined as a new-onset or worsening angina that required hospitalization and was associated with ischemic ST-segment abnormalities, or any elevation of cardiac enzymes, or both.
Non-fatal myocardial infarction and ACS were defined as non-fatal myocardial infarction or ACS occurring more than 1 month after the primary AMI. The target vessel was considered to be the infarct-related coronary artery that was responsible for the AMI at the time of study enrollment. Target-vessel revascularization (TVR) was defined as coronary intervention of this target vessel. Non-TVR was defined as coronary intervention other than on this target vessel. TVR and non-TVR were considered to be driven by ischemia if the stenosis of any vessel was at least $50 \%$ or more of the diameter of the vessel, on the basis of quantitative coronary angiography, in the presence of ischemic signs or symptoms. Congestive heart failure during followup was diagnosed using validated criteria. ${ }^{19}$

The primary study endpoint included long-term incidence of a major adverse cardiovascular event (MACE), defined as cardiovascular death, stroke, non-fatal myocardial infarction or ACS, non-TVR either by coronary artery bypass grafting or PCI, and congestive heart failure that required hospitalization.

The principal secondary endpoint included long-term composite clinical incidence of all-cause death, stroke, nonfatal myocardial infarction or ACS, any revascularizations of either target or non-target vessels, congestive heart failure and peripheral vascular disease that required hospitalization.

\section{Statistical Analysis}

Demographic and baseline characteristics were tabulated as mean $\pm \mathrm{SD}$ for continuous variables, and as numbers and percentages for categorical variables. Comparisons among the classified groups-(1) normal glucose tolerance; (2) abnormal glucose tolerance; (3) previously diagnosed DMwere examined using one-way ANOVA for continuous variables and by a chi-square test for categorical variables. In case of significant $\mathrm{F}$ values for ANOVA, the TukeyKramer test was used for multiple comparisons among groups. Comparisons for postchallenge 2-h glucose levels between normal glucose tolerance and abnormal glucose tolerance were made using the Wilcoxon rank sum test.

We used the Kaplan-Meier method to assess the proportion of patients with events of interest for time-to-event endpoints that included MACE and composite clinical outcomes. Time-to-event among the above 3 groups were compared using a log-rank test. For patients who experienced multiple events, the first event was considered for time-to-event analysis.

In order to examine covariates as possible predictors of MACE, we used a Cox proportional hazard regression model. We modeled candidate predictors as univariates and determined which predictors were significant $(\mathrm{p}<0.20)$. Then, all covariates with $\mathrm{p}$ values $<0.20$ were modeled multivariately using a stepwise procedure. The significant threshold for inclusion and exclusion of independent variables was set at 0.20 . A 2-sided p value less than 0.05 was considered statistically significant. Statistical analysis was performed using SAS-Stat, software from SAS Institute, Cary, NC, USA.

\section{Results}

We enrolled the 275 patients of whom 85 had previously diagnosed DM. The remaining 190 non-DM patients underwent an OGTT at the time of discharge. We completed final visits between September and November 2005. The 
Table 1 Baseline Characteristics of the 3 Patients Groups

\begin{tabular}{|c|c|c|c|c|}
\hline & $\begin{array}{c}\text { Normal glucose } \\
\text { tolerance } \\
(n=78)\end{array}$ & $\begin{array}{c}\text { Abnormal glucose } \\
\text { tolerance } \\
(n=112)\end{array}$ & $\begin{array}{c}\text { Diabetes mellitus } \\
\qquad(n=85)\end{array}$ & $p$ value \\
\hline \multicolumn{5}{|l|}{ Basic characteristics } \\
\hline Age in years (mean, $S D$ ) & $62.5(10.0)$ & $61.6(11.0)$ & $61.9(9.6)$ & 0.83 \\
\hline Men & $60(77 \%)$ & $88(79 \%)$ & $66(77 \%)$ & 0.96 \\
\hline \multicolumn{5}{|l|}{ Previous disorders } \\
\hline MI & $6(8 \%)$ & $15(13 \%)$ & $13(15 \%)$ & 0.31 \\
\hline Hypertension & $43(55 \%)$ & $65(58 \%)$ & $45(53 \%)$ & 0.77 \\
\hline$C A B G$ & $1(1 \%)$ & $2(2 \%)$ & $5(6 \%)$ & 0.14 \\
\hline$P C I$ & $1(1 \%)$ & $6(5 \%)$ & $3(4 \%)$ & 0.34 \\
\hline Stroke & $4(5 \%)$ & $11(10 \%)$ & $3(4 \%)$ & 0.18 \\
\hline Current smoker & $47(60 \%)$ & $70(63 \%)$ & $47(55 \%)$ & 0.59 \\
\hline Hyperlipidemia & $37(47 \%)$ & $75(67 \%)$ & $53(62 \%)$ & 0.13 \\
\hline Family history of $C H D$ & $7(9 \%)$ & $9(8 \%)$ & $5(6 \%)$ & 0.74 \\
\hline \multicolumn{5}{|l|}{ Variable (mean, $S D)$} \\
\hline Peak creatine kinase, IU/L & $3,176(2,249)$ & $3,150(2,185)$ & $3,065(2,465)$ & 0.95 \\
\hline Body-mass index, $\mathrm{kg} / \mathrm{m}^{2}$ & $23.4(3.0)$ & $23.9(2.7)$ & $23.4(4.9)$ & 0.54 \\
\hline Hemoglobin Alc, \% & $5.1(0.4)$ & $5.5(0.6) *$ & $8.0(1.8) * * *$ & $<0.0001$ \\
\hline Admission blood glucose, $\mathrm{mg} / \mathrm{dl}$ & $149.4(34.2)$ & $172.8(57.6)^{*}$ & $286.2(95.4) * * *$ & $<0.0001$ \\
\hline Fasting plasma glucose, $\mathrm{mg} / \mathrm{dl}$ & $93.6(9.0)$ & $99.0(12.6)$ & $140.4(34.2)^{* * *}$ & $<0.0001$ \\
\hline 2- $h$ plasma glucose, $\mathrm{mg} / \mathrm{dl}$ & $109.8(30.6)$ & $183.6(37.8) *$ & $n / a$ & $<0.0001$ \\
\hline Cholesterol, $\mathrm{mg} / \mathrm{dl}$ & $196.1(39.0)$ & $201.9(30.9)$ & $200.7(40.9)$ & 0.57 \\
\hline HDL-cholesterol, $\mathrm{mg} / \mathrm{dl}$ & $42.5(9.7)$ & $40.1(11.2)$ & $40.1(9.3)$ & 0.28 \\
\hline LDL-cholesterol, $\mathrm{mg} / \mathrm{dl}$ & $129.3(35.5)$ & $131.2(27.0)$ & $132.0(35.9)$ & 0.89 \\
\hline Triglycerides, $m g / d l$ & $122.1(55.8)$ & $153.1(68.1)^{*}$ & $143.4(48.7)$ & 0.003 \\
\hline
\end{tabular}

Data are presented as number (\%) unless otherwise indicated.

$M I$, myocardial infarction; $C A B G$, coronary artery bypass graft; PCI, percutaneous coronary intervention; CHD, coronary heart disease; HDL, high-density lipoprotein; $L D L$, low-density lipoprotein.

${ }^{*} p<0.05$ vs normal glucose tolerance, ${ }^{* *} p<0.05$ vs abnormal glucose tolerance.

Table 2 Treatment During Hospital Stay and at Discharge of the 3 Patients Groups

\begin{tabular}{lcccc}
\hline \hline & $\begin{array}{c}\text { Normal glucose } \\
\text { tolerance } \\
(n=78)\end{array}$ & $\begin{array}{c}\text { Abnormal glucose } \\
\text { tolerance } \\
(n=112)\end{array}$ & $\begin{array}{c}\text { Diabetes mellitus } \\
(n=85)\end{array}$ & $p$ value \\
\hline Thrombolysis & $3(4 \%)$ & $3(3 \%)$ & $6(7 \%)$ & 0.32 \\
Primary PCI & $22(28 \%)$ & $30(27 \%)$ & $17(20 \%)$ & 0.42 \\
$\quad$ POBA & $45(58 \%)$ & $70(63 \%)$ & $51(60 \%)$ & 0.80 \\
Stents & $76(97 \%)$ & $110(98 \%)$ & $82(96 \%)$ & 0.74 \\
Aspirin & $44(56 \%)$ & $66(59 \%)$ & $48(56 \%)$ & 0.92 \\
Ticlopidine & $60(77 \%)$ & $95(85 \%)$ & $70(82 \%)$ & 0.38 \\
B-blockers & $64(82 \%)$ & $89(79 \%)$ & $74(87 \%)$ & 0.38 \\
ACE inhibitors & $14(18 \%)$ & $12(11 \%)$ & $14(16 \%)$ & 0.32 \\
Calcium channel blockers & $8(10 \%)$ & $12(11 \%)$ & $13(15 \%)$ & 0.53 \\
Diuretics & $20(26 \%)$ & $46(41 \%)$ & $24(28 \%)$ & 0.05 \\
Statin & $0(0 \%)$ & $20(18 \%)$ & $66(78 \%)$ & $<0.0001$ \\
Oral hypoglycemic agents & $0(0 \%)$ & $0(0 \%)$ & $6(7 \%)$ & 0.004 \\
Insulin therapy & & & \\
\hline
\end{tabular}

Data are presented as number (\%) unless otherwise indicated.

ACE, angiotensin-converting enzyme; POBA, plain old balloon angioplasty. Other abbreviation see in Table 1.

median follow-up interval was 5.3 years.

Among all patients, $34(12 \%)$ had a previous myocardial infarction and $18(7 \%)$ had a history of stroke (Table 1). The patients without previously diagnosed DM were divided into 2 groups: 78 with normal glucose tolerance and 112 patients with newly diagnosed abnormal glucose tolerance (IGT; $n=77, \mathrm{DM} ; \mathrm{n}=35$ ). When the fasting plasma glucose criteria were applied, however, only $12 \%(\mathrm{n}=22)$ of individuals without previously diagnosed DM were diagnosed as IFG. There was only 1 patient with isolated IFG (with no IGT). Among patients with newly-diagnosed abnormal glucose tolerance, only 21 of $112(19 \%)$ showed IFG, so the remaining $81 \%$ patients showed isolated postchallenge hyperglycemia.
There were no differences in the prevalence of cardiovascular risk factors or cardiovascular co-morbidity among these 3 groups (Table 1). The enzymatic infarct size was similar among 3 groups. Patients with abnormal glucose tolerance showed several differences when compared to patients with normal glucose tolerance. These included higher values of 2-h post-load plasma glucose and triglycerides. The type of reperfusion therapy for AMI was similar among the groups. Subsequent treatments did not differ significantly among the 3 groups except for statin, which was prescribed most frequently in the group with abnormal glucose tolerance (Table 2).

Clinical events in relation to glucometabolic status are summarized in Table 3. Clinical events due to coronary 
Table 3 Events in Relation to Glucometabolic Status

\begin{tabular}{lcccc}
\hline \hline Type of event & $\begin{array}{c}\text { Normal glucose } \\
\text { tolerance } \\
(n=78)\end{array}$ & $\begin{array}{c}\text { Abnormal glucose } \\
\text { tolerance } \\
(n=112)\end{array}$ & $\begin{array}{c}\text { Diabetes mellitus } \\
(n=85)\end{array}$ & Total \\
\hline Death & $2(0)$ & & & \\
$\quad$ Non-cardiovascular & $2(0)$ & $3(0)$ & $3(0)$ & $10(0)$ \\
$\quad$ Cardiovascular & $2(0)$ & $4(2)$ & $2(1)$ & $8(1)$ \\
Stroke & $3(0)$ & $12(1)$ & $9(2)$ & $24(3)$ \\
Non-fatal MI or ACS & $2(2)$ & $7(4)$ & $6(4)$ & $15(10)$ \\
CABG & $12(10)$ & $17(16)$ & $21(21)$ & $50(47)$ \\
PCI & $2(1)$ & $16(3)$ & $17(9)$ & $35(13)$ \\
TVR & $1(1)$ & $5(1)$ & $8(3)$ & $14(5)$ \\
Non-TVR & $0(0)$ & $2(0)$ & $2(0)$ & $4(0)$ \\
Heart failure & $12(5)$ & $33(8)$ & $36(17)$ & $69(30)$ \\
Peripheral vascular disease & $23(14)$ & $54(22)$ & $49(35)$ & $126(71)$ \\
Sum of MACE & & & \\
Sum of secondary endpoints & & & & \\
\hline
\end{tabular}

Table summarizes events that occurred until death or November 25, 2005.

Data are presented as numbers (during the first year). Each event was recorded only once.

ACS, acute coronary syndrome; TVR, target vessel revascularization; MACE, major adverse cardiovascular event. Other abbreviations see in Table 1.

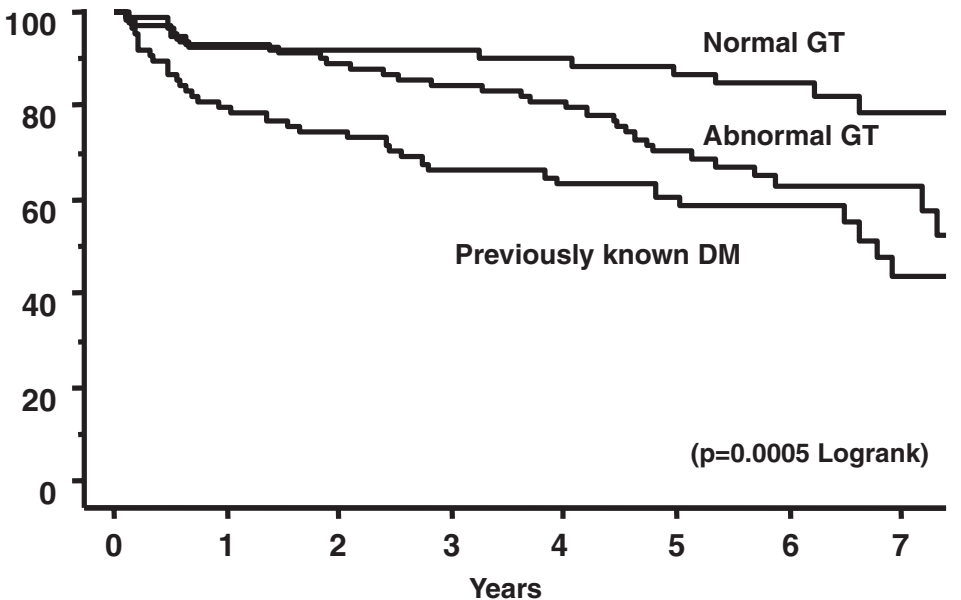

$\begin{array}{lrllllllr}\text { Normal GT } & 78 & 66 & 59 & 58 & 54 & 47 & 32 & 18 \\ \text { Abnormal GT } & 112 & 91 & 77 & 70 & 64 & 49 & 25 & 15 \\ \text { Previous DM } & 85 & 63 & 56 & 48 & 45 & 38 & 21 & 9\end{array}$

Fig 1. Kaplan-Meier estimate of time to the primary end point among the 3 patient groups. GT, glucose tolerance; DM, diabetes mellitus; Previous DM $85 \quad 63$

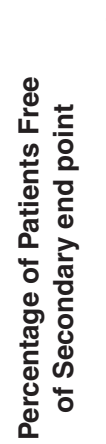

No. at Risk Normal GT Abnormal GT Previous DM

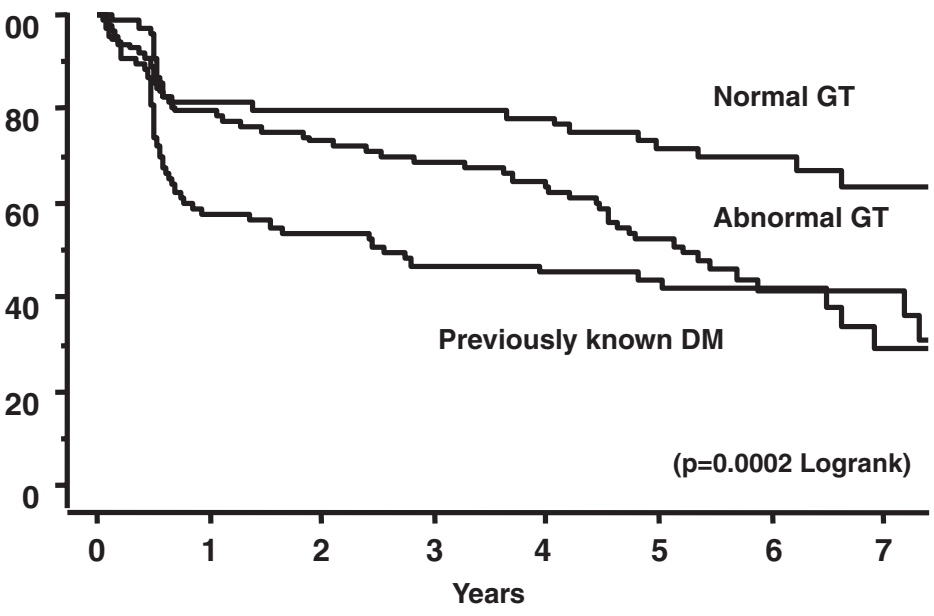

$\begin{array}{rrrrrrrr}78 & 57 & 52 & 51 & 48 & 41 & 28 & 16 \\ 112 & 77 & 65 & 58 & 52 & 39 & 15 & 8 \\ 85 & 44 & 40 & 34 & 32 & 26 & 13 & 6\end{array}$

Fig 2. Kaplan-Meier estimate of the time to the principal secondary outcome among the 3 patient groups. GT, glucose tolerance; DM, diabetes mellitus. 
Table 4 Candidate Predictors Related to MACE Among the 3 Groups

\begin{tabular}{|c|c|c|c|c|}
\hline \multirow[b]{2}{*}{ Variables } & \multicolumn{2}{|c|}{ Univariate analysis } & \multicolumn{2}{|c|}{ Multivariate analysis } \\
\hline & $\begin{array}{c}\text { Hazard ratio } \\
(95 \% C I)\end{array}$ & $p$ value & $\begin{array}{c}\text { Hazard ratio } \\
(95 \% C I)\end{array}$ & $p$ value \\
\hline \multicolumn{5}{|l|}{ Glucometabolic status } \\
\hline Normal glucose tolerance & 1 & & 1 & \\
\hline Abnormal glucose tolerance & $2.48(1.28-4.78)$ & 0.0068 & $2.65(1.37-5.15)$ & 0.004 \\
\hline Previous diabetes & $3.23(1.67-6.24)$ & 0.0005 & $3.27(168-6.38)$ & 0.0005 \\
\hline Previous CABG surgery & $4.25(1.83-9.84)$ & 0.0009 & $3.86(1.65-9.04)$ & 0.0018 \\
\hline Fasting plasma glucose & $1.01(1.00-1.02)$ & 0.001 & & \\
\hline Admission blood glucose & $1.00(1.00-1.01)$ & 0.0181 & & \\
\hline History of MI & $1.87(1.08-3.23)$ & 0.0252 & & \\
\hline Statins & $0.59(0.35-0.99)$ & 0.0452 & $0.56(0.33-0.94)$ & 0.0293 \\
\hline Hemoglobin Alc & $1.12(0.99-1.26)$ & 0.0516 & & \\
\hline Previous stroke & $1.78(0.92-3.46)$ & 0.0882 & & \\
\hline Diuretics & $1.64(0.92-2.92)$ & 0.0918 & & \\
\hline Age & $1.02(0.99-1.04)$ & 0.1436 & & \\
\hline Hypertension & $1.37(0.87-2.15)$ & 0.1739 & & \\
\hline
\end{tabular}

Results are from a univariate Cox regression for variables with $p<0.20$.

CI, confidence interval. Other abbreviations see in Tables 1-3.

segments that were not responsible for the primary AMI increased after 1 year in patients with abnormal glucose tolerance and those with previously diagnosed DM. As shown in Fig 1, there was a persistent and significant increase in the risk of MACE in patients with abnormal glucose tolerance and those with previous DM. The cardiovascular event-free survival rate in the abnormal glucose tolerance group was $70 \%$ at 5-year-follow up, which was significantly lower than the rate in normal glucose tolerance group $(87 \%, \mathrm{p}=0.0085)$ and equivalent to the previously diagnosed DM group $(60 \%, \mathrm{p}=0.09)$. In the abnormal glucose tolerance group, the cardiovascular event-free survival rate was similar between IGT and the newly diagnosed DM subgroups (73\% and 67\%, $\mathrm{p}=0.99$ ) at 5 -year-follow up.

As shown in Fig 2, in all groups, the secondary composite clinical outcome within the first year depended mainly on the repeated revascularization of the primary target vessel that showed restenosis, resulting in rapid deceleration during the first year. Over the following years, however, events related to these target-vessels occurred less frequently. The event-free survival from the secondary composite endpoints in the abnormal glucose tolerance group was $52 \%$ at 5-yearfollow up, which was significantly lower than that for the normal glucose tolerance group $(72 \%, \mathrm{p}=0.0027)$ and not much different from the previously diagnosed DM group $(44 \%, \mathrm{p}=0.13)$.

The incidence of MACE was related to several variables identified using a simple Cox regression (Table 4). The best prediction of a future cardiovascular event, according to multiple Cox regression analysis, was achieved using a model that included previous coronary artery bypass surgery, glucometabolic status and prescriptions of statin (Table 4). In this Cox model, the relative risk of MACE was 2.65 (95\% confidence interval $(\mathrm{CI}): 1.34-5.15, \mathrm{p}=0.004)$ in the group with abnormal glucose tolerance and 3.27 (95\% CI: $1.68-6.38, \mathrm{p}=0.0005$ ) in the group with previously diagnosed DM when compared with the normal glucose tolerance group.

\section{Discussion}

The present study confirmed that glucometabolic abnormality, as determined by the presence of postchallenge hyperglycemia, was one of the most powerful predictors of long-term cardiovascular events in Japanese patients with AMI, and an OGTT is recommended to identify these patients accurately.

\section{Prevalence of DM and IGT in AMI Patients}

The high prevalence $(72 \%)$ of impaired glucometabolic status (previously diagnosed DM, $31 \%$; and, newly diagnosed abnormal glucose tolerance, $41 \%$ ) was evident in the present study based on AMI patients in the Japanese population. The actual prevalence might be much higher because we excluded nearly one-third of patients whose medical condition was complicated by in-hospital cardiovascular events and/or renal insufficiency. Conversely, less than $30 \%$ of patients were categorized as having normal glucose tolerance as determined by the $75 \mathrm{~g}$ OGTT 14 days after the onset of AMI, when their cardiovascular condition was fully stabilized. Therefore, consistent with the data from the GAMI study in Sweden, a substantial proportion of patients with AMI might have abnormal glucose metabolism.14 Also, the Euro Heart Survey on diabetes and the heart demonstrated that $36 \%$ of patients had impaired glucose regulation and 22\% had newly detected DM in patients with acute coronary artery disease ${ }^{20}$ Using 134 Japanese patients with AMI/ACS but with no previous DM (normal levels of $\mathrm{HbAlc}$ and fasting glucose), Hashimoto et al reported that $10 \%$ of subjects had DM and $37 \%$ were IGT/IFG using a $75 \mathrm{~g}$ OGTT? ? $^{1}$ Taken together, the prevalence of abnormal glucometabolic status in Japanese patients with cardiovascular disease is much higher than we expected, and it may be not much different from that occurring in Caucasian populations ${ }^{14}$

\section{Prognosis of AMI Patients With Abnormal Glucometabolic Status}

The lowest rate of MACE was observed in the group with normal glucose tolerance. More importantly, there were no differences in the MACE rates between newly-diagnosed abnormal glucose tolerance and previously diagnosed DM groups during the long-term follow up after AMI. Our results are consistent with the GAMI study by investigators in Sweden, although there were substantial differences in study populations and backgrounds 15 These differences included: (1) they did not include subjects with established DM; (2) their undiagnosed DM patients were defined by 
blood glucose levels less than $200 \mathrm{mg} / \mathrm{dl}$ on admission; and (3) most of their patients did not receive acute reperfusion therapy during the course of their AMI!1 Therefore, racial differences or modest differences in study conditions are not likely to have affected our major finding that the abnormal glucometabolic status is a strong predictor of long-term outcomes. In the present study, patients were evaluated at the first endpoint and repeated cardiovascular events were not considered. DM and asymptomatic fasting hyperglycemia after AMI may increase the risk of the repeated future cardiovascular events.

The 5-year mortality of $6.5 \%$ in our subjects was equivalent to the 1-year mortality of $6.5 \%$ in patients with known DM and random blood glucose $<200 \mathrm{mg} / \mathrm{dl}$ reported in the Improving Cardiovascular Outcomes in Nova Scotia (ICONS) project.22 Also, our mortality rate was much lower than that reported as $11 \%$ for patients with no previous DM in the GAMI group ${ }^{15}$ However, patients older than 80 , with renal insufficiency or in-hospital cardiovascular complications were precluded from the present study. These conditions might have been the cause of decreased mortality among the study subjects. More frequent interventions using acute reperfusion therapy could be another factor underlying the reduced mortality in the present study population.

\section{Early Detection of Abnormal Glucometabolic Status}

Our data is consistent with others on the point that patients with postchallenge hyperglycemia carry an increased risk of cardiovascular morbidity and mortality. Early detection of abnormal glucose tolerance would, therefore, permit the initiation of secondary preventive programs in such patients.

The Diabetes Epidemiology Collaborative Analysis of the Diagnostic Criteria in Europe (DECODE) study showed that abnormalities in 2-h glucose were better predictors of mortality from all-cause mortality and from cardiovascular and non-cardiovascular disease than fasting glucose alone?,13 In the present study, 91 patients $(81 \%)$ with newly-diagnosed abnormal glucose tolerance showed normal fasting plasma glucose levels; hence, less than $20 \%$ of patients had apparent IFG. These lines of evidence consistently point to the critical importance of an OGTT assessment of postchallenge hyperglycemia after AMI, although the measurements of fasting plasma glucose and $\mathrm{HbAlc}_{1}$ still dominate screening in current clinical settings 23

\section{Hyperglycemia and Cardiovascular Injury}

The STOP-Noninsulin-Dependent Diabetes Mellitus trial demonstrated that decreasing postprandial plasma glucose levels in IGT patients by ana-glucosidase inhibitor reduced progression to overt DM as well as the risk of cardiovascular events, which further supported a detrimental role for high blood glucose levels on the cardiovascular system?24,25 Ceriello et al and others have shown that postprandial hyperglycemia is associated with an increase in tissue oxidative stress.6-29 This appeared to be true not only for DM patients, but also for individuals with IGT30,31 Hyperglycemia-induced oxidative stress might induce endothelial dysfunction, resulting in pathological damage to the cardiovascular system. ${ }^{32,33}$ In the present study, patients with previously diagnosed DM and fasting hyperglycemia were excluded, so we demonstrated a high prevalence of postchallenge hyperglycemia in Japanese patients with AMI, and, patients with postchallenge hyperglycemia after AMI were at high risk of future cardiovascular disease.

In the present study, patients with abnormal glucose tolerance showed higher levels of triglycerides and were prescribed more statins than those with normal glucose tolerance. Since hypertriglyceridemia is one of the established factors contributing to metabolic syndrome, this risk factor together with abnormal glucose tolerance could affect outcomes among patients with AMI34,35 With statistical analyses, the hypertriglyceridemia appeared not to be an independent determinant of long-term prognosis. However, it should be noted that patients with metabolic syndrome could be more common in this particular group.

In the multivariate analysis, glucometabolic status, together with a previous coronary artery bypass surgery and managements without statins, remained as the only risk predictors. However, patients with abnormal glucose tolerance were prescribed more statins than those with normal glucose tolerance. Several large, randomized, controlled trials have demonstrated that cholesterol-lowering therapy with statins reduces the risk of death or cardiovascular events across a wide range of cholesterol levels ${ }^{36-38}$ In the present study, the attending physician prescribed statins to our patients according to the dosage recommendation in Japan. Recent study revealed that, among patients who have recently had an ACS, an intensive lipid lowering stain regimen provides greater protection against death or major cardiovascular events than does a standard regimen. 39 An intensive lipid-lowering therapy may affect long-term the clinical prognosis in AMI patients with newly diagnosed abnormal glucose tolerance.

We did not include TVR as the primary clinical endpoint in the present study. Actually, the present study shows that coronary events due to progression in segments other than the AMI-responsible lesion are persistently increased after 1 year in patients with abnormal glucose tolerance and those with previously diagnosed DM. Thus, increased MACE rates in these groups are related to the growing number of novel coronary lesions.

\section{Study Limitations}

First, abnormal glucose tolerance during admission due to AMI could be influenced by the stress induced by this acute condition. Norhammar et al showed there is an equivalent diagnostic value in the post-load 2-h blood glucose level examined on the third or fourth day of AMI, and at 3 months after discharge ${ }^{14}$ In the present study, the OGTT was performed an average of 14 days after the onset of AMI, when the effects of acute circulating stress and systemic inflammatory processes were likely to be negligible. In addition, most of the patients underwent acute coronary revascularization, which terminated repetitive ischemic attacks.

Second, we excluded 109 (28\%) patients, most of whom had major in-hospital complications. It is conceivable that this particular group of patients were had much higher DM rates. In those patients, however, OGTT can not be performed during admission and precise glucometabolic status can not be evaluated. Thus, we assume that the actual frequency of DM was prominent in our patient population.

Third, we did not make repeated evaluations of glucometabolic status. Thus, we do not know how many patients with IGT developed overt DM during the observation period. Although the follow-up study may further elucidate time-dependent changes in glucometabolic status and its effects on the cardiovascular outcome, we feel that it is 
important to detect abnormal glucose regulations in those patients during the hospital phase. Some reports have shown that baseline IGT is an independent risk predictor for future cardiovascular events, which is not confounded by the subsequent development of diabetes. ${ }^{40}$

Lastly, because our subjects were mostly Japanese, caution is needed in extrapolating our results to other ethnic groups. However, we assume that compared to typical Caucasians, our population is exposed to an equivalent risk of an abnormal glucometabolic state and its consequences.

\section{Conclusions}

Newly-diagnosed abnormal glucose tolerance predicts long-term cardiovascular events in Japanese patients with AMI. Its adverse prognostic impact is as large as that of previously diagnosed DM. Patients with abnormal glucose tolerance are almost 2.7-fold more likely to have subsequent cardiovascular events during the 5-year-follow up period than those with normal glucose tolerance after AMI. Since patients admitted due to AMI are ideal audiences for life style modulations and risk stratifications, it is incumbent on all physicians who care for these AMI patients not only to revascularize the responsible coronary lesions, but also to utilize this opportunity for the initiation of effective secondary prevention programs.

\section{Acknowledgements}

We gratefully thank Ms. Yukiko Imai for her statistical assistance. We also thank Mr. Shozo Miki for his critical reading of the English in the manuscript.

\section{References}

1. Woodfield SL, Lundergan CF, Reiner JS, Greenhouse SW, Thompson MA, Rohrbeck SC, et al. Angiographic findings and outcome in diabetic patients treated with thrombolytic therapy for acute myocardial infarction: The GUSTO-I experience. J Am Coll Cardiol 1996; 28: $1661-1669$

2. Kosuge M, Kimura K, Kojima S, Sakamoto T, Matsui K, Ishihara M, et al. Effects of glucose abnormalities on in-hospital outcome after coronary intervention for acute myocardial infarction. Circ J 2005; 69: $375-379$

3. Harjai KJ, Stone GW, Boura J, Mattos L, Chandra H, Cox D, et al. Comparison of outcomes of diabetic and nondiabetic patients undergoing primary angioplasty for acute myocardial infarction. Am J Cardiol 2003; 91: 1041-1045.

4. Mukamal KJ, Nesto RW, Cohen MC, Muller JE, Maclure M, Sherwood JB, et al. Impact of diabetes on long-term survival after acute myocardial infarction: Comparability of risk with prior myocardial infarction. Diabetes Care 2001; 24: 1422-1427.

5. Pyorala K, Savolainen E, Lehtovirta E, Punsar S, Siltanen P. Glucose tolerance and coronary heart disease: Helsinki policemen study. $J$ Chronic Dis 1979; 32: 729-745.

6. Fuller JH, Shipley MJ, Rose G, Jarrett RJ, Keen H. Coronary-heartdisease risk and impaired glucose tolerance: The Whitehall study. Lancet 1980; 1: 1373-1376.

7. The DECODE study group. European Diabetes Epidemiology Group. Diabetes Epidemiology: Collaborative analysis Of Diagnostic criteria in Europe. Glucose tolerance and mortality: Comparison of WHO and American Diabetes Association diagnostic criteria. Lancet 1999; 354: $617-621$.

8. Haffner SM, Mykkanen L, Festa A, Burke JP, Stern MP. Insulinresistant prediabetic subjects have more atherogenic risk factors than insulin-sensitive prediabetic subjects: Implications for preventing coronary heart disease during the prediabetic state. Circulation 2000; 101: $975-980$.

9. Coutinho M, Gerstein HC, Wang Y, Yusuf S. The relationship between glucose and incident cardiovascular events: A metaregression analysis of published data from 20 studies of 95,783 individuals followed for 12.4 years. Diabetes Care 1999; 22: 233-240.

10. Hanefeld M, Fischer S, Julius U, Schulze J, Schwanebeck U, Schmechel H, et al. Risk factors for myocardial infarction and death in newly detected NIDDM: The Diabetes Intervention Study, 11-year follow-up. Diabetologia 1996; 39: 1577-1583.

11. Barrett-Connor E, Ferrara A. Isolated postchallenge hyperglycemia and the risk of fatal cardiovascular disease in older women and men: The Rancho Bernardo Study. Diabetes Care 1998; 21: 1236-1239.

12. Temelkova-Kurktschiev TS, Koehler C, Henkel E, Leonhardt W, Fuecker K, Hanefeld M. Postchallenge plasma glucose and glycemic spikes are more strongly associated with atherosclerosis than fasting glucose or HbA1c level. Diabetes Care 2000; 23: 1830-1834.

13. DECODE Study Group, the European Diabetes Epidemiology Group. Glucose tolerance and cardiovascular mortality: Comparison of fasting and 2-hour diagnostic criteria. Arch Intern Med 2001; 161: $397-405$.

14. Norhammar A, Tenerz A, Nilsson G, Hamsten A, Efendic S, Ryden $\mathrm{L}$, et al. Glucose metabolism in patients with acute myocardial infarction and no previous diagnosis of diabetes mellitus: A prospective study. Lancet 2002; 359: 2140-2144.

15. Bartnik M, Malmberg K, Norhammar A, Tenerz A, Ohrvik J, Ryden L. Newly detected abnormal glucose tolerance: An important predictor of long-term outcome after myocardial infarction. Eur Heart $J$ 2004; 25: 1990-1997.

16. Alberti KG, Zimmet PZ. Definition, diagnosis and classification of diabetes mellitus and its complications. Part 1: Diagnosis and classification of diabetes mellitus provisional report of a WHO consultation. Diabet Med 1998; 15: 539-553.

17. Report of the Expert Committee on the Diagnosis and Classification of Diabetes Mellitus. Diabetes Care 1997; 20: 1183-1197.

18. Friedewald WT, Levy RI, Fredrickson DS. Estimation of the concentration of low-density lipoprotein cholesterol in plasma, without use of the preparative ultracentrifuge. Clin Chem 1972; 18: 499-502.

19. Ho KK, Anderson KM, Kannel WB, Grossman W, Levy D. Survival after the onset of congestive heart failure in Framingham Heart Study subjects. Circulation 1993; 88: 107-115.

20. Bartnik M, Ryden L, Ferrari R, Malmberg K, Pyorala K, Simoons M, et al. The prevalence of abnormal glucose regulation in patients with coronary artery disease across Europe: The Euro Heart Survey on diabetes and the heart. Eur Heart J 2004; 25: 1880-1890.

21. Hashimoto K, Ikewaki K, Yagi H, Nagasawa H, Imamoto S, Shibata $\mathrm{T}$, et al. Glucose intolerance is common in Japanese patients with acute coronary syndrome who were not previously diagnosed with diabetes. Diabetes Care 2005; 28: 1182-1186.

22. Wahab NN, Cowden EA, Pearce NJ, Gardner MJ, Merry H, Cox JL. Is blood glucose an independent predictor of mortality in acute myocardial infarction in the thrombolytic era? J Am Coll Cardiol 2002; 40: $1748-1754$.

23. Groeneveld Y, Petri H, Hermans J, Springer MP. Relationship between blood glucose level and mortality in type 2 diabetes mellitus: A systematic review. Diabet Med 1999; 16: 2-13.

24. Chiasson JL, Josse RG, Gomis R, Hanefeld M, Karasik A, Laakso M. Acarbose for prevention of type 2 diabetes mellitus: The STOPNIDDM randomised trial. Lancet 2002; 359: 2072-2077.

25. Chiasson JL, Josse RG, Gomis R, Hanefeld M, Karasik A, Laakso M. Acarbose treatment and the risk of cardiovascular disease and hypertension in patients with impaired glucose tolerance: The STOPNIDDM trial. JAMA 2003; 290: 486-494.

26. Ceriello A, Bortolotti N, Motz E, Crescentini A, Lizzio S, Russo A, et al. Meal-generated oxidative stress in type 2 diabetic patients. Diabetes Care 1998; 21: 1529-1533.

27. Ceriello A, Quagliaro L, D'Amico M, Di Filippo C, Marfella R, Nappo F, et al. Acute hyperglycemia induces nitrotyrosine formation and apoptosis in perfused heart from rat. Diabetes 2002; 51: 10761082.

28. Ceriello A, Mercuri F, Quagliaro L, Assaloni R, Motz E, Tonutti L, et al. Detection of nitrotyrosine in the diabetic plasma: Evidence of oxidative stress. Diabetologia 2001; 44: 834-838.

29. Ceriello A, Taboga C, Tonutti L, Giacomello R, Stel L, Motz E, et al. Post-meal coagulation activation in diabetes mellitus: The effect of acarbose. Diabetologia 1996; 39: 469-473.

30. Marfella R, Quagliaro L, Nappo F, Ceriello A, Giugliano D. Acute hyperglycemia induces an oxidative stress in healthy subjects. J Clin Invest 2001; 108: 635-636.

31. Ceriello A, Bortolotti N, Falleti E, Taboga C, Tonutti L, Crescentini A, et al. Total radical-trapping antioxidant parameter in NIDDM patients. Diabetes Care 1997; 20: 194-197.

32. Heitzer T, Schlinzig T, Krohn K, Meinertz T, Munzel T. Endothelial dysfunction, oxidative stress, and risk of cardiovascular events in patients with coronary artery disease. Circulation 2001; 104: 2673 2678.

33. Kawano H, Motoyama T, Hirashima O, Hirai N, Miyao Y, Sakamoto $\mathrm{T}$, et al. Hyperglycemia rapidly suppresses flow-mediated endothe- 
lium-dependent vasodilation of brachial artery. J Am Coll Cardiol 1999; 34: 146-154.

34. Expert Panel on Detection, Evaluation, And Treatment of High Blood Cholesterol In Adults (Adult Treatment Panel III). Executive Summary of The Third Report of The National Cholesterol Education Program (NCEP). JAMA 2001; 285: 2486-2497.

35. Kasai T, Miyauchi K, Kurata T, Ohta H, Okazaki S, Miyazaki T, et al. Prognostic value of the metabolic syndrome for long-term outcomes in patients undergoing percutaneous coronary intervention. Circ $J$ 2006; 70: $1531-1537$.

36. The Scandinavian Simvastatin Survival Study (4S). Randomised trial of cholesterol lowering in 4444 patients with coronary heart disease. Lancet 1994; 344: 1383-1389.

37. Sacks FM, Pfeffer MA, Moye LA, Rouleau JL, Rutherford JD, Cole TG, et al. The effect of pravastatin on coronary events after myocardial infarction in patients with average cholesterol levels: Cholesterol and Recurrent Events Trial investigators. N Engl J Med 1996; 335: $1001-1009$.

38. The Long-Term Intervention with Pravastatin in Ischaemic Disease (LIPID) Study Group. Prevention of cardiovascular events and death with pravastatin in patients with coronary heart disease and a broad range of initial cholesterol levels. N Engl J Med 1998; 339: 13491357.

39. Cannon CP, Braunwald E, McCabe CH, Rader DJ, Rouleau JL, Belder R, et al. Intensive versus moderate lipid lowering with statins after acute coronary syndromes. N Engl J Med 2004; 350: $1495-$ 1504.

40. Qiao Q, Jousilahti P, Eriksson J, Tuomilehto J. Predictive properties of impaired glucose tolerance for cardiovascular risk are not explained by the development of overt diabetes during follow-up. Diabetes Care 2003; 26: 2910-2914. 